\title{
WORKSHOP PENINGKATAN JIWA WIRAUSAHA GUNA MENAMBAH NILAI EKONOMI KELUARGA MELALUI PEMANFAATAN POTENSI DAERAH
}

\author{
Fidyah Jayatri ${ }^{1)}$, Triwilujeng Ayuningtyas ${ }^{2)}$, Dwi Yanuarindah Putri ${ }^{3)}$, Roni Wiranata ${ }^{4)}$ \\ STKIP PGRI Lumajang \\ fidyah.jaya3@gmail.com,triwi53@yahoo.com,dwi.y.putri@gmail.com*, roniwiranat@yahoo.com
}

\begin{abstract}
The purpose of this PKM activity is a workforce that has not worked in Bedayu village, Senduro sub-district, Lumajang Regency. So far, entrepreneurship has been conveyed only through socialization to increase public awareness about the importance of entrepreneurship as a way to reduce high unemployment. But in reality socialization alone is not enough to make people motivated and interested in entrepreneurship. The method of implementing the PKM Economic Education Study Program embodies the entrepreneurship workshop program in a combination of hard skills and soft skills in the form of a combination of educational socialization about entrepreneurship and training to manage the potential of the Bedayu village area to improve the economic status of the community. The human resource competency program (hardskill) is related to how to cultivate the potential of the Bedayu community. While soft skills are related to the development of simple entrepreneurship that can be done in the easiest way accompanied by how to package and calculate the profits to be gained. The result of community service activities is the achievement of soft beds from the Bedayu village community for their interest in carrying out home-based entrepreneurial activities by creating business opportunities in the form of coffee products and marketing outside the Bedayu region
\end{abstract}

Keywords: Entrepreneurship; family economy; regional potential
Submit
Diterima
13 Juli 2020
25 Juli 2020
Dipublikasikan
31 Juli 2020

DOI : https://doi.org/10.33503/pambudi.v4i01.866

\section{ANALISIS SITUASI}

Keluarga mempunyai fungsi ekonomi seperti halnya yang dikemukakan oleh Sudjana (2004) “...memberi makna bahwa keluarga merupakan ekonomi, akitvitas berkaitan dengan upaya mencari nafkah, membina dan mengembangkan usaha keluarga, perencanaan pendapatan, dan pengeluaran biaya keluarga. Pada gilirannya kegiatan dan status ekonomi keluarga mempengaruhi harapan orang tua dan anakanaknya terhadap masa depan kehidupan mereka."

Produktivitas ekonomi masyarakat akan semakin baik ketika setiap orang mampu untuk membangun sebuah paradigma usaha mandiri dalam bentuk kegiatan wirausaha. Sehubungan dengan hal tersebut maka wirausaha merupakan potensi pembangunan bagi sebuah negara, karena dengan membuka lapangan kerja yang lebih luas maka kegiatan pemerintah akan sangat terbantu utamanya dalam mengentaskan pengangguran sehingga sebuah negara bisa lebih produktif (Jayatri, 2018).

Lebih lanjut, Jhon Kao (dalam Saiman, 2017) yang menjelaskan bahwa wirausaha adalah usaha menciptakan nilai melalui pengenalan kesempatan bisnis, manajemen pengambilan resiko yang tepat, dan melalui keterampilan komunikasi serta manajemen untuk memobilisasi manusia, uang bahan bahan baku yang diperlukan untuk menghasilkan proyek supaya terlaksana dengan baik. Sehingga dengan diadakannya workshop ini tidak hanya melatih bagaimana menjadi seorang wirausaha namun juga memberikan nilai tambah kepada pendidikan ekonomi dalam keluarga. Menurut Goode (1995), keberhasilan atau prestasi yang dicapai seseorang dalam pendidikannya tidak 
hanya memeprhatikan mutu dari institusi pendidikan saja, tetapi juga memperhatikan keberhasilan keluarga dalam memberikan anak-anak mereka persiapan yang baik untuk bagi pendidikan yang dijalani. Begitu juga dengan penjelasan yang dikemukakan oleh Rifai (2009) keluarga sebagai lembaga sosial terkecil berkembang menjadi lembaga ekonomi, psikologis, pendidikan, pembangunan sosial lemasyarakatan, pembenagunan kehidupan beragama yang perlu dijalankannya dalam arah dan tujuan mencapai keluarga bahagia dan sejahtera."

Pengabdian kepada masyarakat (PKM) adalah salah satu dari tiga unsur Tri Dharma Perguruan Tinggi, mengutamakan kepada aktivitas nyata yang dilakukan oleh dosen sehingga keberadaannya di tengah masyarakat dapat memberikan manfaat, khususnya warga masyarakat yang berada di lokasi PKM. Berangkat dari pemberian manfaat inilah tim PKM Prodi Pendidikan Ekonomi tergerak untuk melakukan pembinaan dan pelatihan kepada masyarakat di desa Bedayu Kecamatan Senduro Kabupaten Lumajang.

Kegiatan ini bekerja sama dengan mahasiswa KKN angkatan 2014 dimana melalui hasil pengamatan mereka kegiatan wirausaha merupakan kegiatan yang sulit untuk dilakukan. Kurangnya pemahaman masyarakat Bedayu tentang wirausaha yang sederhana sebagai bentuk usaha bagi peningkatan ekonomi keluarga mereka. Banyaknya potensi alam yang dimiliki masyarakat nyatanya tidak membuat mereka tertarik untuk mengolah SDA yang ada.

Menurut Joshep Schumpeter dalam Alma, Buchari (2016) wirausaha adalah kegiatan yang mendobrak sistem ekonomi yang ada dengan memperkenalkan barang dan jasa yang baru, meciptakan organisasi baru atau mengolah bahan baku baru. Dari sinilah muncul sebuah gagasan, pentingnya dilaksanakan kegiatan pengabdian bagi kalangan masyarakat yang jauh dari jangkuan STKIP PGRI Lumajang. Oleh karena itulah kami memiliki berinisiatif melakukan edukasi tentang wirausaha sekaligus praktek pengolahan bahan baku yang berpotensi di desa Bedayu.

Pendekatan kegiatan mengacu pada proses pemberdayaan sumber daya manusia yang dilakukan melalui usaha peningkatan kemampuan, penyuluhan, pelatihan, pembimbingan, dan pendampingan bagi masyarakat agar memiliki kemampuan, keterampilan, dan sikap positif untuk meningkatkan derajat kehidupan melalui pemahaman wirausaha dan edukasinya. Seperti halnya yang dikemukakan oleh Suryana (2006) seseorang dikatakan menjadi wirausahawan adalah mereka yang kompeten dalam bidang ilmu pengetahuan, keterampilan, dan kualitas individu itu sendiri meliputi motivasi, nilai, sikap, serta tingkah laku yang diperlukan dalam melakukan kegiatan.

Metode penyampaian bahan penyuluhan dan pelatihan dalam kegiatan pengabdian kepada masyarakat ini adalah presentasi oleh narasumber pengolah kopi, tanya jawab narasumber dengan peserta, diskusi, dan workshop.

\section{METODE PELAKSANAAN}

Metode yang digunakan dalam kegiatan ini menggunakan pola tatap muka secara langsung antara usahawan yang merupakan alumni STKIP PGRI Lumajang guna memberikan wawasan serta keterampilan mengolah kopi di Bedayu, Kecamatan Senduro Kabupaten Lumajang. Tim pengabdian kepada masayarakat memberikan penjelasan terkait usaha yang akan dirintis, dilanjutkan dengan tanya jawab dan praktik pembuatan usaha kopi bagi angkatan kerja yang masih mengganggur tidak terkecuali para ibu rumah tangga.

\section{Waktu Pengabdian}

Pengabdian masyarakat ini

berlangsung pada

Tanggal : 4 September 2017 s.d

6 September 2017 


$\begin{array}{ll}\text { Pukul } & : 09.00 \text { s.d selesai } \\ \text { Tempat } & : \text { Kantor Desa Bedayu } \\ & \text { Kecamatan Senduro }\end{array}$

Sasaran

Sasaran kegiatan pengabdian kepada masyarakat ini adalah terealisasinya program PKM STKIP PGRI Lumajang Program Studi Pendidikan Ekonomi bersinergi dengan kegiatan KKN mahasiswa sebagai bentuk pendampingan bagi pengembangan suatu wilayah secara integral dan terpadu dilingkungan kabupaten Lumajang.

Melalui asas kerjasama atau kemitraan antara STKIP PGRI Lumajang dengan masyarakat desa Bedayu Kecamatan Senduor, kegiatan PKM ini dilaksanakan sebagai implementasi dari salah satu cara dalam peningkatan perekonomian yang didorong oleh LPPM STKIP PGRI Lumajang yaitu meningkatkan kemampuan mahasiswa melalui kegiatan $\mathrm{KKN}$ dalam memecahkan permasalahan masyarakat dan pengembangan wilayah melalui kegiatan pelatihan pembuatan pudding oleh masyarakat desa.

\section{Prosedur Pelaksanaan PKM}

Secara garis besar, prosedur pelaksanaan kegiatan pengabdian kepada masyarakat ini dilakukan melalui serangkaian kegiatan sebagai berikut:

1) Identifikasi masalah di lapangan,

2) Pembentukan tim PKM,

3) Kerjasama dengan pengusaha pembuat kopi rumahan yang merupakan alumni STKIP PGRI Lumajang sebagai narasumber

4) Pembuatan proposal PKM

5) Koordinasi antara tim PKM dengan khalayak sasaran,

6) Pelaksanaan kegiatan ( sosialisasi, dan praktek mengolah kopi) serta pemantauan lebih lanjut bagi masyarakat yang mau memulai usaha kopi,

7) Pembuatan laporan PKM dan tindak lanjut.

\section{Luaran yang dihasilkan dalam kegiatan ini adalah :}

a. Mengembangkan usaha yang sedang tim PKM jalankan.

b. Menganalisa peluang usaha dan memiliki jiwa kewirausahaan.

c. Membantu tim PKM dalam pengembangan usaha seperti,penambahan modal dari pihak lain.

d. Sebagai alat komunikasi dalam memaparkan dan meyakinkan pentingnya berwirausaha.

e. Menghasilkan produk dan dapat dinikmati tanpa harus banyak mengeluarkan biaya

\section{HASIL DAN PEMBAHASAN}

Kelangkaan (scarcity) mengacu pada sumber daya yang terbatas atau langka yang menyebabkan barang dan jasa tidak bisa dihasilkan seperti yang diinginkan. Dengan memahami maksud dan tujuan dipelajarinya ilmu ekonomi didepan penting kiranya kita perlu melakukan pengembangan ilmu ekonomi dalam rangka mengisi peluang untuk menciptakan usaha baru dalam memenuhi kebutuhan yang mana sumber daya bersifat langka (Jayatri, 2018).

Peluang untuk menciptakan usaha baru nampaknya tidak hanya membutuhkan sosialisasi saja namun betul-betul memerlukan bentuk nyata melalui praktek secara langsung. Realisasi program workshop wirausaha dalam perpaduan dari hardskill dan softskill yang bentuknya adalah perpaduan sosialisasi pendidikan tentang berwirausaha dan pelatihan untuk mengelola potensi daerah desa Bedayu disambut hangat oleh warga yang kala itu memang banyak yang tidak bekerja.

Permasalahan yang ada dimasyarakat Bedayu meliputi:

a. Hasil bumi desa Bedayu berupa kopi hanya sebagai tanaman hias di pekarangan rumah, ketika panen kopi masyarakat membiarkan rontok dan terbuang 
b. Biji kopi diolah sebagai minuman keluarga bagi mereka yang tahu cara mengolahnya, namun sebagian besar lebih suka menikmati kopi yang terjual di pasar

c. Ketidaktahuan untuk memasok kopi yang dimiliki membuat masyarakat tidak peduli untuk mengembangkan tanaman tersebut sebagai bahan sebuah usaha yang mengahasilkan

d. Pemahaman masyarakat Bedayu untuk memulai wirausaha terasa sulit dilakukan

e. Kurangnya pemahaman masyarakat Bedayu tentang wirausaha yang sederhana sebagai bentuk usaha rumahan yang dapat bernilai ekonomis

Berangkat dari masalah tersebut, tim PKM berinisiatif untuk melakukan beberapa tahapan pengabdian yang sudah dijelaskan dalam prosedur pengabdian. Hal ini dilaksanakan agar masyarakat termotivasi dan tergerak untuk mau memulai usaha meskipun dalam lingkup yang sederhana.

Seperti yang disampaikan oleh Gomes (2005) Manajemen Sumber Daya Manusia merupakan suatu gerakan pengakuan terhadap pentingnya unsur manusia sebagai sumber daya yang cukup potensial yang perlu dikembangkan sedemikian rupa sehingga mampu memberikan kontribusi yang maksimal bagi organisasi dan pengembangan dirinya.

Melihat pengertian Manajemen SDM yang dijelaskan oleh Gomes sehingga tim PKM melaksanakan kegiatan ini dengan beberapa tahapan.

Tahapan kegiatan inti dilaksanakan dalam tiga hari kerja meliputi:

a. Proses sosialisasi untuk memberikan kemampuan softskill yang diberikan dalam bentuk presentasi oleh narasumber mengenai wawasan pengolahan produk kopi yang kreatif serta cara menghitung modal awal sampai profit dari penjualan kopi. b. Pelatihan mengolah kopi dan pemasaran kopi bagi masyarakat yang memiliki tanaman kopi

c. Pemantauan lebih lanjut kegiatan usaha yang dibantu oleh mahasiswa KKN angkatan 2014.

Berikut foto-foto kegiatan yang sudah dilaksanakan selama kegiatan berlangsung.

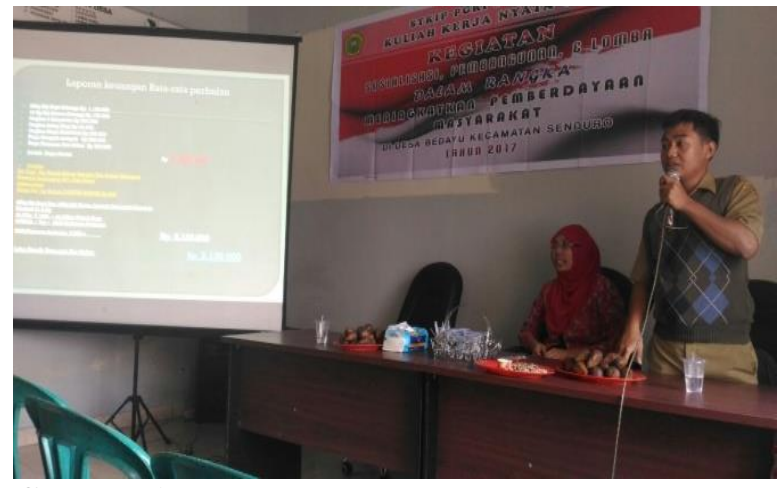

Gambar 1. Pelatihan softskill dari narasumber

Menurut Hardi (2010) Soft skills menunjuk pada indicator seperti kreativitas, sensitifitas, intuisi yang lebih terarah pada kualitas personalyang berada di balik perilaku seseorang.

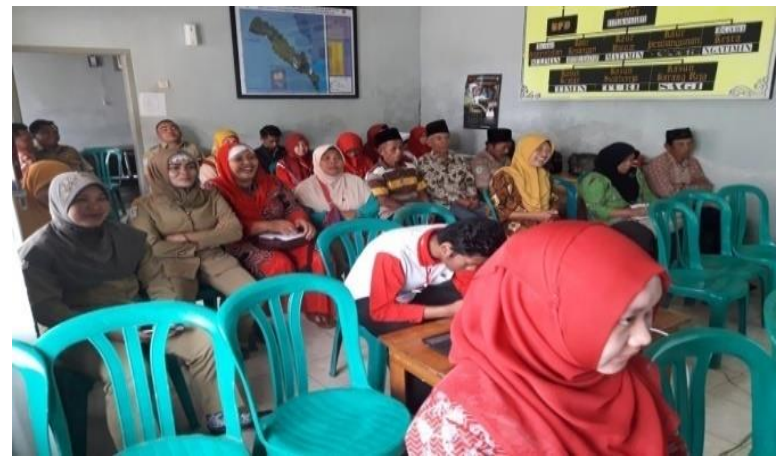

Gambar 2. Antusiasme warga menyimak penjelasan narasumber

Pelatihan softskill menjelaskan bagaimana narasumber mengawali memulai usaha sampai cara menghitung profit dari penjualan kopi yang sudah dilakukan. Proses ini memakan waktu setengah hari dan dilanjutkan dengan praktek mengolah kopi rumahan yang sederhana seperti gambar berikut. 


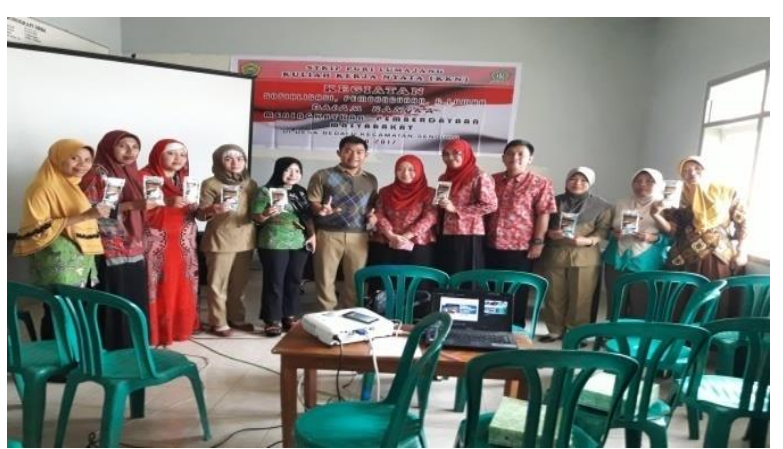

Gambar 3. Pelatihan hardskill praktek pengolahan kopi

Menurut Alam (2012) hard skills merupakan pengetahuan dan kemampuan teknis yang dimiliki seseorang.

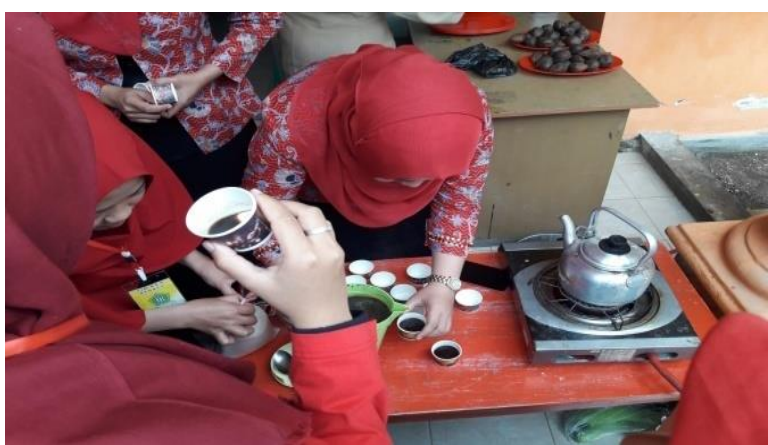

Gambar 4. Seduhan kopi kurma yang sudah jadi

Pemberian pelatihan mengolah kopi dari narasumber menambah antusias warga untuk belajar secara langsung bagaimana mengkombinasikan biji kopi dan biji kurma dalam satu rasa. Untuk mempersingkat waktu narasumber sudah menyiapkan segala bahan jadi biji kopi dan biji kurma yang sudah disangrai kemudian hanya perlu difinishing untuk proses penumbukan dan penyajian kopi.

Bagian proses menyajikan kopi ini sangat ditunggu warga karena penasaran bagaimana rasa biji kopi dan biji kurma yang tercampur dalam satu rasa. Usaha narasumber yang sangat kreatif ini, menjadikan warga antusias untuk mencoba membuat variasi kopi lainnya di rumah. Tim juga membagikan produk dari narasumber yaitu kopi kurma kepada semua warga yang hadir sebagai salah satu penyemangat untuk mau memulai berwirausaha. Berikut foto kebersamaan tim PKM bersama warga dan juga mahasiswa KKN.

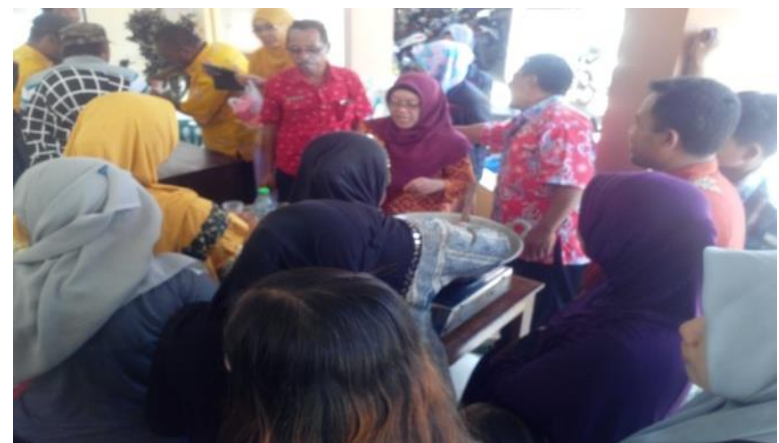

Gambar 5. Kekompakan tim PKM bersama warga

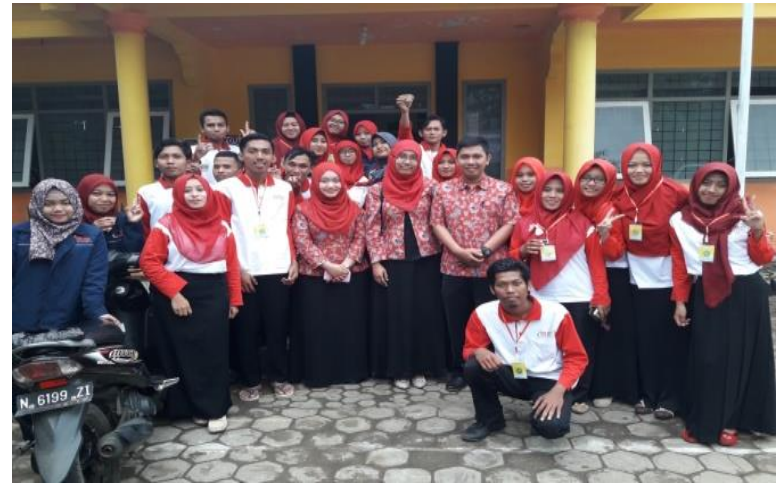

Gambar 6. Kekompakan Tim PKM bersama mahasiswa KKN

Di hari selanjutnya tim PKM bagian lapangan bekerjasama dengan mahasiswa KKN desa Bedayu melaksanakan pemantauan rutin terkait geliat usaha masyarakat desa terkait pengembangan kopi mereka. Berdasarkan hasil pantuan kegiatan pengabdian di desa Senduro, Kabupaten Lumajang meliputi:

a. Masyarakat mulai mengumpulkan biji kopi siap panen yang dikoordinir kepala desa untuk dijual kepada pedagang kopi

b. Alumni STKIP PGRI Lumajang yang bertindak sebagai narasumber memiliki akses untuk mendapatkan sumberdaya kopi dari masyarakat desa Bedayu dengan harga yang sangat terjangkau

c. Terbentuk sinergi antara pemasok bahan baku kopi dan juga pegiat usaha kopi

d. Masyarakat belum seluruhnya tergerak untuk memulai usaha mandiri karena sudah nyaman dengan pekerjaan sebelumnya.

e. Kopi yang biasanya terbuang mulai dimanfaatkan untuk minuman keluarga.

Fidyah Jayatri- Workshop Peningkatan Jiwa Wirausaha Guna Menambah Nilai Ekonomi Keluarga Melalui Pemanfaatan Potensi Daerah 
Sejalan dengan hasil penelitian Jayatri (2019) telah ditemukan bahwa kegiatan wirausaha memiliki beberapa manfaat yaitu mandiri dalam berusaha sehingga mereka tidak tergantung pada orang lain dan jam kerja bisa disesuaikan dan juga bisa membantu perekonomian dari keluarga karena masih banyak keinginan yang belum tercapai.

\section{KESIMPULAN}

Kesimpulan dari kegiatan kegiatan yang kami lakukan dapat diketahui bahwa masyarakat sangat memerlukan kegiatan seperti ini. Masyarakat secara langsung dapat memiliki gambaran nyata bagaimana cara memulai usaha, trik apa yang dibutuhkan, bagaimana cara mengolah dan juga memasarkan produk yang sudah dibuat. Pengalaman ini bisa menjadi dasar ketika masyarakat berniat membuka usaha baru. Kegiatan ini menjadikan alat komunikasi dan hubungan dibidang dunia usaha antara masyarakat dengan narasumber, serta meyakinkan masyarakat pentingnya berwirausaha dalam menghasilkan produk yang dapat dinikmati sendiri bagi keluarga maupun untuk memberikan tambahan nilai ekonomi keluarga.

\section{Ucapan Terima Kasih}

Ucapan terima kasih ditujukan kepada berbagai pihak yang membantu tercapainya kegiatan pengabdian ini. Terima kasih kami sampaikan kepada :

a. LPPM STKIP PGRI Lumajang yang telah memberikan pendanaan terkait kegiatan ini

b. Kepala desa Bedayu, Kecamatan Senduro-Kabupaten Lumajang yang membuka ruang bagi tim PKM untuk berbagi ilmu

c. Warga desa Bedayu, Kecamatan Senduro yang sangat antusias dalam menyambut kedatangan Tim PKM

d. Mahasiswa KKN angkatan 2014 Prodi Pendidikan Ekonomi dan Prodi Pendidikan Matematika STKIP PGRI Lumajang

\section{DAFTAR PUSTAKA}

Alam. 2012. Analisa Pengaruh Hard Skill, Soft Skill, dan Motivasi terhadap Kinerja Tenaga Penjualan (Studi pada Tenaga Kerja Penjualan PT. BUMIPUTERA Wilayah Semarang. Universitas Diponegoro, Fakultas Ekonomi dan Bisnis.

Alma, Buchari. 2016. Kewirausahaan Untuk Mahasiswa dan Umum. Bandung: Alfabeta

Gomes, F. Cardosa. 2005. Manajemen Sumber Daya Manusia. Yogyakarta: Andi Offset.

Goode, William J. 1995. Sosiologi Keluarga (The Family). Terjemahan Laila Hanom Hasyim. Jakarta Bumi Aksara.

Hardi. 2010. Kontribusi Soft Skills dalam Menumbuhkan Jiwa Kewirausahaan. Jurnal STIE Vol. 3 No. 5 Juli 2010.

Jayatri, Fidyah. 2018. Rasionalitas Konsumen: Teori dan Penerapan.

Malang: Unidha Press

Jayatri, Fidyah. (2019). Analisis Potensi Minat Wirausaha Mahasiswa Akhir Prodi Pendidikan Ekonomi Di STKIP PGRI LUMAJANG. Economic \& Education Journal, 2019 (1), 1-9.

Rifai, MSS. 2009. Pendidikan Keluarga dalam Ali M., Ibrahim R, Sukmadinata, dan RAsjidin W (penyunting). Ilmu dan Aplikasi Pendidikan 4. Bandung: Pedagogiana Press. Hal 81 -94.

Saiman, Leonardus. 2009. Kewirausahaan Teori, Praktik dan Kasus-Kasus. Jakarta: Salemba Empat.

Sudjana, D. 2004. Pendidikan Luar Sekolah: Wawasan, Sejarah Perkembangan, Falsafah, Teori Pendukung, Asas. Bandung: Falah Production.

Suryana. 2006. Kewirausahaan Pedoman Praktis, Kiat dan Proses Menuju Sukses. Jakarta: Salemba Empat. 